\title{
FORMADOR EXTERNO: QUAL O SENTIDO DE SUA ATUAÇÃO EM PROGRAMAS DE FORMAÇÃO CONTINUADA ${ }^{1}$
}

\author{
Renata Barroso de Siqueira Frauendorf ${ }^{2}$ \\ Guilherme do Val Toledo Prado ${ }^{3}$
}

INTRODUÇÃO

[...]O que nos faz pessoas não é o Bilhete de Identidade. O que nos faz pessoas é aquilo que não cabe no Bilhete de Identidade. $O$ que nos faz pessoas é o modo como pensamos, como sonhamos, como somos outros[...]".

Mia Couto

Nos últimos anos, em nosso país, o cenário da educação pública brasileira passou, e passa, por constantes mudanças. Essas transformações orientam-se na busca de uma educação que contribua para que a população possa ampliar o repertório cultural e ascender econômica e socialmente, incrementando a ideia de um país fortalecido e em franco desenvolvimento. Principalmente na mídia e nos discursos políticos das diferentes instâncias públicas, sejam municipais, estaduais ou federais, há um ponto comum quando se trata de propostas e ações para a educação pública: a preocupação com a formação continuada de professores e profissionais da área. Esses planos partem, muitas vezes, de análises, pesquisas e estudos que depositam os problemas todos ou quase todos - na péssima qualidade do ensino, elegendo infelizmente, na maioria das vezes, a figura dos professores e profissionais da educação como os grandes responsáveis por essa qualidade.

Como solução para o que é identificado, sugerem investimentos na formação continuada desses profissionais, atribuindo à mesma a responsabilidade por sanar, quase que de "forma milagrosa", todas as dificuldades e entraves que perpassa a educação brasileira.

\footnotetext{
${ }^{1}$ Parte deste artigo foi apresentada no V Seminário de Educação Brasileira (SEB): "Mudanças Atuais na Sociedade Brasileira e o Sistema Nacional de Educação: qualidade da educação pública como direito humano" e publicado no ebook organizado pelo CEDES, em 2015, com o título "Breves considerações do papel do Formador Externo no âmbito dos programas de formação continuada". Editora Cia do Ebook.Timburi, SP: 2015.
}

${ }^{2}$ Faculdade de Educação. Universidade Estadual de Campinas. E-mail: rsfrauendorf@globo.com

${ }^{3}$ Faculdade de Educação. Universidade Estadual de Campinas. E-mail: gvptoledo@gmail.com 
Com essa nova demanda, aparece o profissional especializado, ou "assessor (a) de formação permanente". Este profissional vem substituir a figura do "especialista externo à escola", que geralmente vinha de outras instituições com pouca ou nenhuma experiência escolar. Dentro desta nova perspectiva este assessor traz em seu repertório um conjunto de saberes referentes à prática na instituição consolidando uma assessoria entre pares. Cabe ao assessor de formação permanente atender as demandas dos professores e profissionais da educação de uma determinada escola ou instituição educativa, com o sentido de aprimorar e desenvolver processos de ensino, em colaboração, que atendam as necessidades de aprendizagem dos educandos. (IMBERNON, 2011, p. 92)

No Brasil, esse profissional tem sido denominado como formador externo ${ }^{4}$ em vários programas de formação continuada.

O formador externo, geralmente, faz parte de uma equipe vinculada a uma instituição, pública ou privada, e tem como uma de suas atribuições orientar, provocar, apoiar, instrumentalizar, a equipe em formação, seja na secretaria, seja na escola e demais espaços escolares, a potencializar as ações educativas e a aprimorar os processos de ensino e de aprendizagem. A ação desse profissional varia de acordo com as representações sociais que possui sobre o professor e demais profissionais da educação (SOLIGO, GRANDIN, ALEXANDRINO, 2008), além da concepção de formação que norteia toda a sua ação, pois por trás de ações, há sempre um conjunto de ideias que as orienta, "mesmo quando ele não tem consciência dessas ideias, dessas concepções, dessas teorias, elas estão presentes" (WEISZ, 1999).

Neste artigo pretendemos refletir sobre o sentido da atuação do formador externo no âmbito dos programas de formação continuada e problematizar em que medida essa atuação pode contribuir para o fortalecimento de uma instituição cada vez mais próxima ao que se espera de uma escola no século XXI.

\section{FORMAÇÃO CONTINUADA: UM MESMO TERMO PARA DIVERSOS SENTIDOS...}

\footnotetext{
4 Neste texto, denominaremos como formador externo o profissional especializado que presta serviço para esses programas de formação continuada e que não é vinculado ao quadro da escola ou secretaria de educação. Esse formador pode atuar diretamente ou não com professores, coordenadores, professor - formador e outros profissionais da educação em diferentes segmentos como educação infantil, ensino fundamental e etc.
} 
Ao recuperar as transformações que o termo formação continuada foi sofrendo, fica evidente que as mudanças de nome não são independentes. As alterações de sentido da palavra - de treinamento à formação continuada ou permanente, colaborativa, em serviço - revelam o processo de constante transformação e vitalidade que a linguagem vai percorrendo, de acordo com Vygotsky (2001). De sorte um processo dialógico de geração de significação produzido pelos diferentes indivíduos que viveram, estudaram e pesquisaram essa ideia no campo educacional. Ou seja, as distintas formas de fazer referência à formação continuada aventam práticas e políticas e não apenas um campo de palavras bonitas, como diz Nóvoa (2007, p.22).

Nos anos 1970, segundo Perrenoud (1997), Weisz (2000) e Nóvoa (2002), acreditava-se que um bom professor era aquele que lançava mão de um conjunto de técnicas eficientes para ensinar seus alunos. Era visto como um mero executor de tarefas, um cumpridor de ordens da instituição. Ainda não era entendido como alguém que poderia produzir conhecimentos, tomar decisões de forma autônoma e ética.

Nessa perspectiva um profissional que não dominava ou não se enquadrava naquele princípio talvez tivesse duas possibilidades: ser dispensado da instituição, ou ser treinado para dominar o conhecimento que não dispunha. A formação continuada era concebida como um treinamento, uma situação na qual o sujeito que dominava alguma nova técnica de ensino a transferia, ensinava para o sujeito por ele formado. Resumindo: o treinamento servia para o professor aperfeiçoar as técnicas e executar melhor a sua tarefa de ensinar.

Segundo Libâneo (1997, p.98),

O final da década de 60 e o início da década de 70, é o período em que o chamado "tecnicismo educacional" adquire nova roupagem, no contexto do regime militar instaurado no Brasil em 1964, agora mais explicitamente assentado no behaviorismo e na teoria de sistemas. Essa tendência deixará sua marca mais nos aspectos formais da organização escolar e didática e menos em termos de concepção de ensino, mas irá influenciar boa parte dos projetos governamentais e dos estudos na área de educação.

É possível vislumbrar o cenário da época e compreender de onde nasce a ideia de formação continuada como um recurso para tornar a aula mais atraente ou ainda um artifício para deixar mais claro o conteúdo que se espera que os alunos aprendam. Nesses termos temos em suma: um conteúdo para ser aplicado, um professor aplicador e um aluno passivo! 
Já entre os finais dos anos 1980 e início dos anos 1990, a Educação passou por grandes reformas influenciadas pelas modificações sociais, econômicas e políticas que estavam acontecendo no Brasil e no mundo.

Em um ambiente de transformações, as declarações públicas, leis e muitos dos planos governamentais foram elaborados objetivando centrar a atenção dos profissionais em questões relacionadas à aprendizagem do aluno e não mais na conduta do docente, de forma que as mudanças propostas saíssem do âmbito das discussões e fossem incorporadas à prática educacional. A expectativa era a de um professor que olhasse para como o aluno aprende. Por este ponto de vista a concepção de formação continuada vai se afastando da ideia de uma "ação pela qual um sujeito criador dá forma, estilo ou alma a um corpo indeciso e acomodado" (FREIRE, 2010, p.23).

Nessa época, a expressão mais comumente utilizada era capacitação ou ainda qualificação em serviço, uma ação que intencionava compensar as lacunas da formação inicial. Porém, já havia propostas que se apresentavam como uma possibilidade para o profissional se atualizar, conhecer novidades relacionadas às práticas de ensino. A formação acontecia até o professor estar capacitado ou qualificado para exercer suas funções. A mudança de sentido de treinamento para capacitação também trouxe a necessidade de um docente mais reflexivo e aberto a uma atualização constante. A ideia não era nova, pois a importância do professor reflexivo já vinha sendo defendida por Freire desde os anos 1960. Entretanto ganha corpo, vozes, estudos; os professores passam a compartilhar atividades, sugestões de planejamento, começam a escrever relatos reflexivos e debruçar-se sobre a própria prática, sobre o que faziam na sua sala de aula (WEISZ, 2000, p.123).

Nesse ambiente que se fortalecia, o professor surge como "centro do processo de formação continuada, atuante como sujeito individual e coletivo do saber docente e participante da pesquisa sobre a própria prática" (ANDRE et al, 1999, p.38). Todo esse movimento no campo educacional também vem como resposta aos efeitos de uma política que atendia a "ética do mercado e não a ética universal do ser humano", como afirma Freire (2010, p.127). Logo a ideia de um profissional especializado, de uma escola atualizada, vem colada ao discurso da eficiência, da qualidade, da competitividade.

Assim, uma nova representação do que é ser bom professor aparece vinculada fortemente ao domínio da tecnologia, ser conhecedor de uma didática inovadora e capaz de responder às necessidades de aprendizagem do aluno. Dessa forma, a instituição que oferecia esses serviços tornava-se mais atrativa. Entendemos que no caso do setor privado, fazer uso desses avanços tecnológicos e pedagógicos pode ter um fim utilitarista de atender apenas aos interesses daqueles 
que detém o poder, fazendo o seu negócio mais lucrativo. Para o setor público, a escola que conta com profissionais atualizados, competentes e que oferece recursos tecnológicos de ponta, em alguns casos, passa a ser mais uma bandeira política do que um compromisso ético, que de fato contribua para o desenvolvimento humano. Muitos programas de formação continuada foram planejados considerando essa lógica, a de atender às necessidades do mercado e não das pessoas, o que indica um problema, por ir contaminando de forma negativa o conceito e a finalidade dessa ação (ARELARO, 2007).

Toda essa política econômica tendia, e ainda tende, a focar no indivíduo. Por isso até então era forte a concepção de uma formação continuada centrada no sujeito, cujo principal eixo era a melhora do sistema educacional por meio de ações pontuais. Eram poucas as experiências que visavam contribuir para o desenvolvimento do profissional docente, para construção de um projeto coletivo de uma instituição inovadora. Essa nova expectativa sobre o que se entende por um bom docente embora fortaleça o individualismo, abre espaço para um profissional que sente necessidade de refletir criticamente sobre a própria prática, fazendo emergir o conceito de profissionalidade docente, ou seja, o professor passa a ser encarado como produtor de conhecimento e, a escola, como um lugar para além da aprendizagem: passa a ser um lugar de vida. E sendo um lugar de vida, há pessoas, há histórias, há experiências. Há indivíduos, em interação, relacionando-se em certos contextos, sob determinadas condições de produção. Enfim todo esse conjunto de vivências que acontecem no cotidiano escolar não podem ser desconsiderado num processo formativo como defende Nóvoa (2002, p.37, p.56).

Em nosso país essa redefinição do papel do professor e de sua profissionalização na construção de uma nova escola passa a ser lei no final de 1996 (BRASIL, LDBEN 9394 - art.61 a 67, 20 de dezembro de 1996) ${ }^{5}$, fomentando a necessidade da formação continuada para os profissionais da educação. Atualmente a formação continuada é um direito que, embora esteja garantido por lei desde 2009, conforme indicado por Saviani (2009), não é compreendido por todos profissionais da mesma forma. Os diferentes sentidos atribuídos por eles revelam muito de toda essa trajetória narrada até este ponto.

É frequente o discurso de muitos professores, coordenadores, diretores, etc. de que formação é apenas para aqueles que não são competentes em seu fazer ou para aqueles que não estão satisfeitos com as formas mais tradicionais de ensinar, conservadoras, e buscam uma pedagogia alternativa, uma prática diferenciada. Nesse discurso transparece, também, a ideia de castigo,

\footnotetext{
${ }^{5}$ Vale ressaltar que a necessidade da formação foi transformada em um direito do professor no ano de 2009, conforme indicado por Saviani (2009).
} 
aborrecimento ou até sinal de incompetência vinculada ao processo formativo (PERRENOUD 1997, p.103). Posicionamento que pode ser compreendido não apenas como sinal de resistência, mas como fruto da história de um conceito em constante transformação, que não merece, ficar aprisionado naquilo que o constitui, mas que não o define, exclusivamente, nesse momento. Combinar sentidos, revisitá-los, ressignificá-los nesses espaços é, pois, uma necessidade da própria formação em serviço. Até porque se deve considerar que essas diferentes concepções de formação continuada coexistem até hoje. Saber dessa história também contribui para que façamos escolhas, sejamos coerentes com o que dizemos, com o que escrevemos e com o que fazemos, como diz Freire (2010, p.103).

Todas essas transformações e questões continuam gerando muitas inquietações, tornando-se objeto de estudos de muitas pesquisas nos últimos anos. André et al (1999) fez uma síntese do conhecimento sobre o tema tomando como base a análise de dissertações e teses defendidas nos programas de pós-graduação na área de educação de nosso país, no período de 1990 a 1996, além de analisar artigos publicados em periódicos da área entre os anos de 1990 a 1997 e pesquisas apresentadas nos GTs de Formação de Professores da Anped, de 1992 a 1998. Este estado da arte sobre a formação de professores no Brasil ratificou a crescente preocupação com a atuação do professor nas séries iniciais do Ensino Fundamental, e identificou que, de modo geral, a formação continuada é definida como:

formação em serviço, enfatizando o papel do professor como profissional e estimulando-o a desenvolver novos meios de realizar seu trabalho pedagógico com base na reflexão sobre a própria prática. Os textos argumentam que, nessa perspectiva, a formação deve se estender ao longo da carreira e deve se desenvolver, preferencialmente, na instituição escolar. (ANDRE et al, 1999, p.308)

Esta é uma definição a qual corroboramos, entretanto encontramos nas palavras de Ferreira a ideia de formação continuada que dialoga mais fortemente com o que tomamos como referência nesse artigo:

a formação corresponde a uma transformação pessoal, interior e ligada à experiência de cada sujeito que se permite - e se possibilita - mudar pelo conhecimento construído neste processo. Assim, é o sujeito que se forma. Dado o nosso permanente inacabamento, estamos destinados a nos formarmos. Porém, embora a formação corresponda a um acontecimento de ordem individual, ninguém se forma sozinho. Formamo-nos na relação e interação com o(s) outro(s). (FERREIRA, 2010, p.05) 
Por fim mais recentemente o alvo da formação continuada foi ampliado e, além de professores, surgem programas em redes públicas voltados para outros atores da instituição. Nesta abordagem mais focada na ideia da instituição inovadora e da construção coletiva de competências, percebeu-se a necessidade de se investir também na formação de coordenadores pedagógicos ${ }^{6}$, diretores, supervisores de ensino, equipes de apoio, considerando-se as especificidades de cada função dentro da escola (GASTALDI, 2012).

No Brasil, em 2000 vivemos a chegada de um novo tempo relacionado à ideia de formação continuada mais pautada numa dimensão de fortalecimento da produção coletiva de conhecimentos por meio do PROFA - Programa de Formação de Professores Alfabetizadores ${ }^{7}$. Este programa oferecia um material que unia teoria e prática, contendo tanto vídeos com situações da prática docente como textos teóricos para estudo ou que traziam toda uma orientação para o formador de como tematizar este material junto ao professor.

Conforme o Guia de Orientações Metodológicas Gerais (2001, p.27):

Se, por um lado, a aprendizagem é um processo pessoal e singular, por outro é fruto de construções também coletivas: muitos conhecimentos resultam de aprendizagens conquistadas coletivamente. O trabalho em colaboração é um poderoso aliado nesse sentido, e muitas evidências têm mostrado que, em situações de real parceria, se conquista um nível superior de conhecimento ao que se poderia conquistar sozinho.

Na sequência do PROFA, vimos surgir, ao longo dos últimos anos, uma enormidade de programas de formação continuada, quer elaborados e oferecidos pelo Ministério de Educação, quer propostos pelas próprias secretarias de educação municipais ou estaduais. Há também os criados e desenvolvidos por instituições, universidades, empresas especializadas, ou ainda em parceria, isto é, secretaria e/ou instituição/universidade/empresa.

Por um lado, são ações importantes, porque desejam contribuir para melhoria da qualidade da educação pública, mas, por outro, provocam descontinuidades, abrem muitos flancos nos sistemas educacionais, uma vez que muitos desses programas são substituídos por outros que pretendem ser mais eficientes, ao prometerem melhores resultados, em menos tempo, e a um custo

\footnotetext{
${ }^{6}$ Coordenador Pedagógico, também denominado como Orientador Pedagógico na rede municipal de Campinas e professor coordenador na rede estadual paulista. Em alguns municípios do Brasil o coordenador também é denominado como supervisor pedagógico.
}

${ }^{7}$ Para saber mais sobre o PROFA consulte o site: http://portal.inep.gov.br/web/provinha-brasil/profa 
menor, ou seja vai -se "de um compromisso prévio não cumprido ao seguinte, sem tomarmos consciência de nossa própria história de fracassos" (FERREIRO, 2012, p.465).

Ações desencontradas como as descritas acima levam, muitas vezes, os profissionais da educação a um retrocesso ou estagnação porque encontrarão, nas práticas mais rotineiras e habituais, a segurança e confiança muitas vezes perdida. Essas atitudes evidenciam que não basta formação para se ter inovação, não basta informação para se garantir a experiência. É preciso um compromisso bem mais sério quando se deseja uma inovação no âmbito institucional o que não ocorrerá apenas com sujeitos bem-intencionados e ações desarticuladas entre as diferentes esferas educacionais.

\section{POR QUE UM FORMADOR EXTERNO?}

"Os indivíduos são entidades singulares em permanente processo de construção - indivíduos diferentes, tentando elaborar um conjunto pessoal, uma rede própria de significados a partir da manifesta e frequentemente contraditória diversidade". Stenhouse, 1997.

A figura de um assessor de formação, formador de formadores - formador externo, não é novidade no contexto educacional e sua presença pode ser identificada desde os anos 70 . Entretanto, até hoje, os sistemas educacionais parecem não aceitar muito bem esse profissional. Entendemos que uma das razões deste formador externo não ser visto com bons olhos, principalmente no contexto escolar, é o fato dele estar associado, na maior parte das vezes, a ações que são impostas pelo poder público, impondo modelos prescritivos que desconsideram os saberes dos docentes, apresentando propostas desenhadas por especialistas que dominam técnicas e teorias que pouco se aproximam das necessidades e práticas do professor e demais profissionais da educação no cotidiano da escola.

O grande desconforto a respeito das avaliações e propostas de ação elaborados por outrem é, precisamente, o fato de não estarem centrados na escola (CANÁRIO, 2005), inseridos no contexto da instituição, o que o faz falar da, e sobre a escola, dificilmente conseguindo estabelecer um diálogo com a escola. Nesse sentido, esses programas de formação continuada acabam por reforçar a

[...] ideia ainda hegemônica de que as universidades, as secretarias de educação e os centros de formação exteriores a escola, são os lócus privilegiados de produção de conhecimento e, portanto, os mais adequados a pensar e propor projetos de formação continuada para a escola. (PRADO, MORAIS e ARAUJO, 2011) 
Um caminho que alguns programas de formação continuada percorrem e que fortalece a ideia do sobrepor, são os programas idealizados embasado em linhas metodológicas mais transmissivas e que tratam de conteúdos variados. Por meio de cursos ou oficinas, isto é, ações pontuais, o formador externo delega, para o professor ou profissionais da escola, a responsabilidade de transformar a teoria em práticas inovadoras, capazes de provocar mudanças na aprendizagem em pouco tempo, perdendo um dos focos principais de sua ação que é, justamente, potencializar a reflexão sobre os diferentes modos de aprender dos alunos. Esses programas tomam a educação como um produto a ser comercializado, pois vendem pacotes de serviços que incluem: projetos de formação continuada, aulas, apostilas ou cadernos para alunos e professores, elaborados a partir da premissa de que tudo serve a todos.

Nesse caso, deposita no outro um [...] "saber não sabido”[...], gerando [...]“locatários e não proprietários do seu próprio saber-fazer.’[...] (CERTAU, 2008, p.143); entende que os participantes dessa formação são alunos e que o formador externo "é aquele que vem dizer" ou que tem papel de informar, explicar, trazer um saber que o outro não dispõe, desconsiderando, na maioria das vezes, a realidade, experiências de trabalho, o cotidiano, enfim a história pessoal e profissional do indivíduo em formação.

Esta visão do formador externo como distante da realidade, descompromissado com o outro, não é à toa. Ela é fruto de experiências, programas e formadores que atuavam e atuam nesse sentido seguindo o princípio de uma racionalidade técnica, como diz Imbernon (2011, p.94). Mas será que todas as parcerias como as indicadas são maléficas para rede pública? Os programas e formadores estão condenados a ficar presos a um passado-presente que não representa o todo? Pode haver sintonia, diálogo entre essas parcerias ou o simples fato delas se constituírem já impede uma outra forma de se pensar?

Mas, se por um lado há tantas razões que não favorecem a ação desse profissional, por outro lado um importante fator que legitima a participação desse formador externo é a possibilidade dele ter um olhar para os problemas da escola de modo mais distanciado, precisamente, por não estar mergulhado nesse espaço-tempo, nas tensões e fazeres do dia a dia escolar. Dessa maneira, ele pode contribuir para que professores e profissionais da escola enxerguem aquilo que às vezes não veem. Como diz Saramago (1995) em seu livro Ensaio sobre a Cegueira o papel atribuído a esse formador pode muitas vezes ser, o de ter "a responsabilidade de ter olhos quando os outros os perderam". Compreendendo aqui esse papel não como excludente ou superior a quem faz e vive a escola, 
apenas diferente, um olhar-pensante que procura formas outras de olhar, como propõe Martins (1995). Uma vez que,
A minha forma se exercita, se instrumentaliza na quebra das amarras de um olhar comum, na procura consciente da própria forma de olhar, no exercício de buscar ângulos novos, na construção de relações. (MARTINS, 1995, p. 24).

Ao atuar dessa forma este formador externo movimenta- se como um vento que venha a favor de uma embarcação que muitas vezes se encontra à deriva, e que pode seguir rumo à uma "ilha desconhecida" (SARAMAGO, 1998) .

Essa perspectiva de formação continuada não é entendida com o fim de preencher lacunas e sanar problemas da formação inicial, muito menos se assemelha a uma varinha mágica que tem poderes infalíveis que basta ser girada no ar para que tudo se resolva. Mas sim, como um conjunto de ações importantes para contribuir para formação de profissionais autônomos, que pensam e refletem sobre a própria prática no contexto de atuação. Nessa perspectiva, o formador externo no lugar de ser o expert, coloca-se como um parceiro que tem uma trajetória e conhecimento construídos ao longo de sua experiência (CANÁRIO, 2005).

É um profissional que parte de uma escuta atenta a fim de dialogar com a escola à medida em que se interessa, genuinamente, pela produção de conhecimento que dela emana, tornando essa formação um momento propício à reflexão e tomada de decisões conjuntos em que todos os envolvidos tem coisas a aprender. Essas aproximações permitem uma certa intimidade não só com os sujeitos envolvidos, mas também com o contexto, pois parte-se de histórias distintas para a produção de histórias partilhadas. Para este formador externo ganhar voz nesse processo, ele precisa ouvir e voltar o olhar para si e para o que suas histórias contam, além de ouvir e voltar o olhar para aqueles com quem se relaciona e o que essas histórias contam para si (VICENTINI, A.A.F...[ et al], 2008).

Esse percurso do formador baseia-se na homologia dos processos, princípio fundamental da formação continuada (ALARCÃO 1996). Isto é, da mesma forma que buscamos um professor, um coordenador ou um profissional da escola, autônomo e reflexivo, que pensa e repensa sua prática, é fundamental que o formador externo também esteja em contínuo processo de autoformação, investigando sua própria prática e aprendizado, de modo coadunar o que se busca e o que se realiza.

\footnotetext{
${ }^{8}$ O Conto da Ilha Desconhecida - Cia. Das Letras -1998
} 
Enfim este princípio concentra a ideia de que aquilo que é proposto pelo formador externo, assim como suas atitudes, sua forma de organizar o encontro relaciona-se com os mesmos conceitos e referências que o professor ou profissional em educação em formação utilizará mais tarde em sua prática.

Dessa forma,

[...] as modalidades de formação se fazem de fato formativas quando engrandecem de algum modo os sujeitos a quem se destinam, quando acrescentam em conhecimento, em saberes, em sabedoria; quando trazem respostas para suas inquietações; quando remetem a inquietações de outras (SOLIGO e PRADO, 2008, pág.39).

Certamente, um dilema - entre tantos - que se constitui para o formador externo que atua em programas de formação continuada é trabalhar na perspectiva da falta, devido à própria formação que recebem e pela muitas (des)informações que circulam no âmbito educacional.

Geralmente as ações de formação começam pela ausência - discurso comum na área de educação - como falta de condições, falta de professores, falta de recursos, falta de formação. Não que não seja real, aliás muitas vezes [...] a gente se acostuma para não se ralar na aspereza, para preservar a pele 9 . Porém, se partirmos deste discurso, e das ações decorrentes "deste rumo" (SARAMAGO, 1998), os efeitos produzidos vão interferir no sentido de pouco se conseguir enxergar o que realmente é feito, o muito que se produz, e dialogar com o conhecimento construído na e pela escola.

Por isso, a prática de um formador externo deve constituir um conjunto de ações importantes para contribuir na formação de profissionais autônomos, que pensam e refletem sobre a própria prática no contexto de atuação (CANÁRIO, 2005). Entretanto também preocupa o rumo que essa discussão tem tomado e os diferentes sentidos que esse propósito da formação continuada vem ganhando no meio educacional e na sociedade.

Durante minha experiência como formadora externa num programa de formação continuada de iniciativa pública, observo que este desejo de encontrar nas salas de aula o conhecimento adquirido pelo professor na formação provoca, por outro lado, uma nova preocupação quando isso não se observa: entende-se que a formação não funciona, não é boa, não cumpre seu propósito inicial. O que me parece não ser levado em conta é que há programas de formação continuada que são interrompidos antes de finalizar, há outros que mudam seu princípio

9COLASANTI, M -Eu sei mas não devia - http://www.releituras.com/mcolasanti_eusei.asp. ACESSO 25/05/2014. 
a fim de atender a uma cultura que se baseia no ritmo ditado por comerciais de TV, os quais sugerem que a informação pode ser transmitida de forma econômica e intensiva.

(F. 2016, p.73)

Enfim o que nos parece não estar sendo levado em conta também é que os bons professores, como disse Vaillant (2013), que são chamados a assumir esse cargo de formador externo muitas vezes, conhecem muito da relação de ensino-aprendizagem com os alunos, mas desconhecem a relação de ensino-aprendizagem com o adulto-profissional. Engana-se quem achar que é tudo a mesma coisa! Os sujeitos dessas formações não são alunos, eles são profissionais que atuam na sala de aula, que produzem conhecimento e é dessa perspectiva que precisamos partir, como afirma Gouveia (2012, p.37-38),

o professor deve ser visto como um profissional e não como um aluno. O professor é um profissional com uma responsabilidade social definida por sua profissão que é ensinar, com uma experiência prática e um contexto de trabalho. A relação do formador e professor não deve ser de professor e aluno, mas de dois profissionais da educação, com conhecimentos e experiências diferentes, e os dois se corresponsabilizando pela qualidade da aprendizagem dos alunos.

Ou seja, nem tudo é o que parece ser!

O discurso recorrente de que as mudanças não são observadas na escola, de que não se atingiu $100 \%$ das escolas ou ainda que nem todos os professores / coordenadores mudaram suas práticas alimenta a máxima da eficiência corporativa como propulsora das ações de formação continuada. Fortalece-se a premissa da formação como mercado, dos educadores como consumidores vorazes de auto formação, a busca pela qualificação que nunca vem (NOVOA, 2007, p.9). Isso não significa eximir os programas e os formadores de suas responsabilidades, nem considerar que tudo que é proposto é sempre bom e de fato transformador e que nem devemos ter metas, objetivos a serem perseguidos. Defendemos que o esforço deve ser o de chegar ao maior número de profissionais e de crianças, contudo discordamos da ideia de que não atingir uma meta desqualifica todo o processo percorrido.

Compreendemos que diferentes sentidos podem ser produzidos para esse conjunto de palavras: PROGRAMA DE FORMAÇÃO CONTINUADA e FORMADOR EXTERNO. Sentidos que variam conforme as condições de produção, relações, sentimentos dos sujeitos em interação envolvidos nos mais diversos contextos. Olhar por esse prisma é fundamental, para não esvaziar e fragilizar as ações de formação continuada como temos visto acontecer, ultimamente, quando lhes é atribuída a responsabilidade de sanar as dificuldades e entraves que perpassam a educação 
brasileira: a formação continuada é "uma condição necessária, mas não suficiente para a mudança na proposta prática" (LERNER, 1999, p.31).

\section{REPENSAR O PENSAMENTO ${ }^{10}$... OU NOVAS PERGUNTAS PARA VELHAS PREOCUPAÇÕES -}

"Tudo no mundo está dando respostas, o que demora é o tempo das perguntas."

Jose Saramago ${ }^{11}$

Desencontros entre formador externo e professores.

Muitas vezes nesse papel de formador me questiono como diminuir a distância entre o que se fala na formação e o que de fato chega na sala de aula.

Em busca dessa aproximação procuro guardar um tempo para visitar escolas e entrar na sala de aula para observar e assim, me alimentar da realidade. Como costumo dizer: é o momento de colocar o pé no chão da escola!

Sempre combino antes com o coordenador, que combina com a professora, para evitar um mínimo de constrangimento, o que é quase impossivel de acontecer, geralmente quando chego na sala recebo um olhar meio desconfiado do tipo: "O que ela quer justo na minha sala?"

E nesse dia não foi diferente, ao entrar numa sala de $5^{\circ}$ ano, dei um alô para os alunos, conversei, rapidamente, com a professora que me disse que estava trabalhando produção de textos, pois estava desenvolvendo um projeto sobre lendas.

Nossa eu pensei, dei sorte, pois este era, justamente, um dos conteúdos de minhas formações com os coordenadores. Assim fui para um canto da sala, e fiquei observando.

A atividade consistia em copiar uma lenda do livro. Quarenta minutos se passaram num silêncio tenebroso, quatro lousas foram preenchidas e as crianças apenas copiando. Compreendi o que significava para esta professora "produção de texto".

Ao terminar essa quase tortura, no meu ponto de vista, as crianças foram orientadas a pegarem livros ou revistas e, animadamente, dois meninos devoraram a revista Ciência Hoje.

No meio dessa agitação reparei em duas crianças que estavam sentados bem à frente da mesa da professora. Elas tinham uma tarefa diferente, ao me aproximar a professora comentou: "Esses são aqueles que não avançam! Precisam de uma atividade diferenciada. "

Vi um menino com olhar triste separando letras para formar palavras de uma lista. Fiquei ao lado dele por um tempo, e em seguida pedi se poderia ler para mim o que tinha feito. Com aquele mesmo olhar de tristeza me disse: "Eu não sei ler. "Eu perguntei: "e as letras você conhece alguma dessas? "Timidamente apontou a de seu nome, do nome da irmã e estabelecemos uma pequena conversa que nos aproximou um pouco.

Voltei para a lista que tinha feito e pedi que me dissesse onde estava escrito determinada palavra o que ele apontou corretamente logo de cara, nem titubeou... e dessa forma ele foi ganhando confiança, eu fui ficando mais confiante, e diante de meus pedidos ele buscava outras palavras na lista. Mesmo diante de seus equívocos, ele não parava. De minha parte, oferecia pistas que ajudavam a retomar suas reflexões.

10 Inspirado no artigo de Mia Couto - Repensar o pensamento, redesenhando fronteiras - Fronteiras do Pensamento: http://www.fronteirasdopensamento.com.br/canalfronteiras/entrevistas/?16,176. ACESSO 24/08/14.

${ }^{11}$ SARAMAGO, J. Memorial do Convento. (1994) Lisboa, Ed.Reunidos (p.225) http://www.funorte.com.br/files/PDF/biblioteca/memorial-do-convento.pdf.acesso julho2013.

Teias v. 18 • n. 50 • 2017(jul./set.): Conversas sobre formação de professores, práticas e currículos 
Fiquei tão encantada com ele que nem vi quando a professora se aproximou, apenas sei que quando a notei ela já estava ali, observando nossas descobertas.

Nosso tempo infelizmente terminou e aquele olhar triste deu lugar a um imenso sorriso. Achei melhor voltar ao meu lugar e de longe vi quando ele todo orgulhoso se aproximou da professora e perguntou: "E agora o que faço? "E ela respondeu: "Volte ao seu lugar e copie as palavras que você montou. "Eu, por minha vez, "chorei por dentro" ao ouvir a resposta da professora.

Para encerrar esse dia, ao sairmos para o parque me aproximei da professora e ainda num sopro de esperança comentei: "Nossa você viu que bacana que o J. conseguiu ler. Ele leu todas as palavras."

Para o que ela me respondeu: "Também com todas as dicas que você deu, quem não ia ler. "

E diante de sua resposta, não legitimando o que eu tinha feito, chorei por dentro novamente.

$R F$

(Narrativa produzida a partir dos diálogos e reflexões com participantes do Grupo XXX12, no ano de 2011

A narrativa acima diz respeito a uma situação muito frequente vivida na formação continuada - o desencontro entre formador externo e o sujeito da formação. E como é comum esse desencontro! Porquê ambos não partilham de um projeto comum?! Talvez...

Mas para quem a situação acima se traduziu em experiência de acordo com o conceito de Larrosa (2014). Qual dos três sujeitos envolvidos na narrativa passou a saber mais coisas que antes, porque foi tocado, foi provocado?

Olhar para esta cena nos convida a pensar nos caminhos tomados nas atuações de formadores externos e a buscar um diálogo/escuta com as diferentes experiências e oportunidades vividas por eles, o que é validado pelas palavras de SOLIGO (2007, p.13):

[...] o sujeito se forma a partir das oportunidades que tem, aquelas que se convertem em experiências de aprendizagem de fato, a partir de sua história anterior, do que valoriza e deseja, das relações que estabelece com o outro.

O desafio está dado e a questão ainda gira em torno de pensar como estabelecer uma ponte entre o que se faz nas formações e o que acontece na escola; ou seja, qual é a medida entre orientar, apoiar e oferecer espaço para a tomada de decisões pelos sujeitos da formação, principalmente, quando a mesma não acontece dentro da escola?

É fácil encontrarmos culpados para os problemas da escola! O que é fundamental é considerar, radicalmente, o quanto ela é um espaço em constante movimento, com atores que circulam e se revezam nos papéis de protagonistas, a partir de diferentes realidades, saberes,

\footnotetext{
${ }^{12}$ Grupo XXX (XXXXXXXXXXXX), acontece quinzenalmente, e participam professores e profissionais da educação que se reúnem para discutir suas práticas pedagógicas.
}

Teias v. 18 • n. 50 • 2017(jul./set.): Conversas sobre formação de professores, práticas e currículos 
histórias, vivências, concepções que se coadunam, se estranham e, justamente, por isso, basta um pequeno descompasso para levar por "água abaixo" tantas experiências e conhecimentos construídos. É o inusitado que muitas vezes se torna cotidiano...

Diante disso, para evitar conflitos e confrontos, inerentes em um espaço que abriga tão variadas culturas, os diferentes profissionais da escola tendem ao isolacionismo, individualismo, a simplificação, a buscar resultados e a distanciar-se dos parceiros, como se isso fortalecesse a experiência pessoal e dialogasse com o que se espera da escola no século XXI.

Como ocorre em um cenário complexo, as situações problemáticas que nele aparecem não são apenas instrumentais, já que obrigam o profissional da educação a elaborar e construir sentido de cada situação muitas vezes única e irrepetível. (IMBERNON 2011, p.120).

Recorrendo a epigrafe, mais que buscar respostas, os que pensam a formação continuada precisam ir em busca de perguntas, perguntas que possam abrir caminhos, trazer possibilidades e não verdades, pois, certamente, serão elas -as perguntas - que poderão nos levar adiante, a olhar para frente, a perceber em que é preciso avançar ou recuar.

\section{DIANTE DISSO, O QUE É POSSÍVEL PENSAR?}

"Cada um lê com os olhos que tem. E interpreta a partir de onde os pés pisam. Todo ponto de vista é a vista de um ponto. " Leonardo Boff

A escola, e aqueles que fazem a escola, muitas vezes, resistem à incorporação de novidades à sua realidade, como foi o caso da permissão do uso da caneta esferográfica, da entrada de máquinas de datilografia, computadores, diferentes modos de organização de tempo e espaço, até de livros que fogem a um único modelo aceito e legitimado pela cultura dominante na instituição, para citar alguns exemplos.

Entretanto as inovações fazem parte do discurso e da ação de muitos educadores, que acabam não sendo bem vistos nos contextos escolares mais tradicionais e avessos a mudanças, muito provavelmente, porque abre-se uma nova perspectiva ao profissional e seus pares, porque para se experimentar, ousar, é preciso de parceria, colaboração, autonomia; é preciso de tempo, introspecção, reflexão e ação.

O cerne da formação continuada parece ser então, o das relações entre os sujeitos de modo que a escola consiga desassossegar sua própria realidade cultural, além de se oferecer conhecimento didático e práticas inspiradoras. Aliado ainda a uma ideia do professor como sujeito da formação, 
uma vez que é um profissional que possui saberes, fazeres, experiências únicas, que vão tomando corpo e se constituem em conhecimento.

Como propõe IMBERNON (2011, p.86),

\begin{abstract}
Em vez da independência, propor a interdependência; em vez do corporativismo profissional, a abertura profissional; em vez do isolamento, a comunicação; em vez da privacidade do ato educativo, propor que ele seja público; em vez do individualismo, a colaboração; em vez da dependência, a autonomia; em vez da direção externa, a autorregulação e a crítica colaborativa.
\end{abstract}

Essas reflexões nos abrem muitas alternativas e questionamentos sobre o papel do formador externo dentro de programas de formação continuada, e sobre o que se espera dessas ações a favor de uma escola considerando os docentes que temos, os alunos que circulam por estes espaços e os cidadãos que desejamos formar, para atuar de modo respeitoso e democrático na sociedade contemporânea.

Seguramente uma provocação para a formação inicial e continuada dos diferentes profissionais da educação, que ora se apresenta na direção de puxar o freio de emergência como nos sugere W. Benjamin (TÜRCKE, C, 2010, p.303) de modo a segurar essa ânsia em tornar tudo o mais informatizado possível, em transformar a escola nesse ambiente árido em que tudo pode ser resolvido atrás de um monitor, ritmado pelo tempo e duração de comerciais de TV. Nesse prisma, a lei que impera é a de comunicar com brevidade, concisão e veemência da velocidade, como se isso representasse a escola que se almeja para o século atual. Compreendemos que esta visão sequer se aproxima do tempo que se necessita para aprender, se consideramos a aprendizagem como um processo contínuo e inacabado de construção do novo.

Desafio que ora se apresenta a problematizar uma instituição, com ideias que remetem ao século XIX em que o professor, formador, parecem como os únicos detentores de conhecimento, e a escola a única fonte possível para acessá-lo. Uma escola que ainda teima em ignorar as potencialidades que o trabalho em parceria pode proporcionar, e que está presa a modos de avaliação que focam na quantidade de conteúdos aprendidos.

Se olharmos para essa realidade que ainda é muito presente nos dias atuais, surge uma questão fundamental para o formador externo que é colaborar com os professores e profissionais da escola a descobrirem o saber que está implícito em suas experiências a fim de ordenar, justificar, fundamentar, revisar, transformar, descartar, reviver, rememorar e se apropriar destes conhecimentos e saberes profissionais. Contribuir para que, principalmente os professores 
compreendam que o melhor professor de um professor é um outro professor e que para isso o trabalho em parcerias é inevitável.

Afinal, o efeito mais desejado à um formador externo na perspectiva apresentada é apoiar o fortalecimento de uma escola em que os docentes e demais profissionais da educação, considerem que seu maior desafio é despertar no outro o desejo de aprender a aprender, de se tornar um leitor crítico que duvide, critique, relacione, busque informações, conhecimentos que dialoguem com o que já possuem. Uma escola que valoriza e legitima as experiências vividas e partilhadas, que fomenta a capacidade de resolver problemas, de buscar informações e estabelecer relações as mais variadas possíveis, fortalecendo o intercâmbio de ideias, opiniões, entre parceiros mais experientes e menos experientes.

Sujeitos que se descubram inteligentes, capazes de produzir conhecimento, além de comunicar-se de forma engenhosa considerando seu $e u$, mas também em total sintonia com seu próximo, pois será a partir desta relação e intercâmbio com o outro, que ele poderá se tornar cada vez mais humano porque o que nos faz pessoas é o modo como pensamos, como sonhamos, como somos outros, independente de sermos alunos, professores, coordenadores, diretores, supervisores ou formadores externos.

\section{BIBLIOGRAFIA}

ALARCÃO, I.(org.). Formação reflexiva de professores: estratégias de supervisão. Porto: Porto, 1996.

ANDRE, M. et al. O Estado da Arte da formação de professores no Brasil. Educação e Sociedade, [online]. v. 20, n. 68, dez. 1999. p.301-309. http://dx.doi.org/10.1590/S010173301999000300015. Acesso em: 01 jul. 2016.

ARELARO, L. Formulação e implementação das políticas públicas em educação e as parcerias público-privadas: impasse democrático ou mistificação política. Educação e Sociedade [online]. v. 100, n. 28, out. 2007, p.899-919. http://www.scielo.br/pdf/es/v28n100/a1328100.pdf. Acesso em: 06 dez.2016

BRASIL. Senado Federal. Lei de Diretrizes e Bases da Educação Nacional: nº 9394/96. art.61 a 67. Brasília, 1996.

CANÁRIO, Rui. O que é a escola? Um olhar sociológico. Porto: Porto Editora, LDA, 2005.

CERTEAU, M. A invenção do cotidiano: 1.artes de fazer. Petrópolis, RJ: Editora Vozes, 2008, pág.143.

FERREIRA, C.R. Labirinto de perguntas: reflexões sobre a formação de professores na e a partir da escola. Tese (Doutorado) - Curso de Doutorado em Educação, Campinas, SP: Unicamp, 2013. $279 \mathrm{f}$ 
FERREIRO, E. O Ingresso na escrita e nas culturas do escrito: seleção de textos de pesquisa. São Paulo, SP: Cortez, 2013.

FRAUENDORF, R.B.S. A voz de uma professora - formadora que se inventa e reinventa a partir da/com/na escola. Dissertação (Mestrado) - Curso de Mestrado em Educação, Campinas, SP: Unicamp, 2016.170f.

GASTALDI, M.V. Formação continuada na Educação Infantil: possibilidades e desafios na perspectivado formador. Dissertação (Mestrado) - Curso de Mestrado em Educação, São Paulo, SP: Pontifícia Universidade Católica de São Paulo, 2012. 157 f.

GOUVEIA, B.B. Formação dos coordenadores pedagógicos em Boa Vista do Tupim/BA: uma experiência colaborativa, o fio por trás das missangas. Dissertação (Mestrado) - Curso de Mestrado em Educação, Psicologia da Educação, São Paulo,SP : Pontifícia Universidade Católica de São Paulo. 2012. 171 f.

IMBERNON, F. Formação Docente e Profissional: formar-se para a mudança e a incerteza. São Paulo, SP: Cortez, 2011.

LARROSA, J. Tremores: escritos sobre experiência. Belo Horizonte, MG: Autentica Editora, 2014.

LIBANEO, J.C. Educação: Pedagogia e Didática - O campo investigativo da pedagogia e da didática: esboço histórico e buscas de identidade epistemológica e profissional. In: PIMENTA, Selma Garrido (Org.). Didática e Formação de Professores: percursos e perspectivas no Brasil e em Portugal. São Paulo, SP: Cortez, 1997. Cap. 2. p. 77-129.

MARTINS, M.C. O sensível olhar pensante, In WEFFORT,M.F.[et al],(orgs). Observação Registro - Reflexão. Instrumentos Metodológicos I. Série Seminários. São Paulo, SP : Espaço Pedagógico, 1995, págs. 24,25.

PERRENOUD, P. Práticas Pedagógicas, Profissão Docente e formação: Perspectivas Sociológicas. 2. ed. Lisboa, POR: Instituto de Inovação Educacional, 1997. 206 p. 3 v. Coleção Tema de Educação 3.

PRADO, G.V.T; MORAIS, J.F.S. e ARAUJO, M.S. Processos de (Auto) Formação Docente No Cotidiano Da Escola: Horizontes de Possibilidades. In RPD - Revista Profissão Docente, Uberaba, MG, v.11, n. 24, jul/dez. 2011, págs. 53-67.

SAVIANI, D. Formação de professores: aspectos históricos e teóricos do problema no contexto brasileiro. Revista Brasileira de Educação [online] v. 14 n. 40 jan. /abr. 2009, págs. 143-155. http://www.scielo.br/pdf/rbedu/v14n40/v14n40a12.pdf. Acesso em: 06 dez.2016.

SOLIGO, R. Quem forma quem? Instituição dos Sujeitos. Dissertação (Mestrado) - Curso de Mestrado em Educação, Campinas, SP: Unicamp 2007.212 f.

SOLIGO, R e PRADO, G.V.T. Quem forma quem, afinal? In VICENTINI, A. A.F...[ et al], (orgs). Professor - formador: Histórias Contadas e cotidianos vividos. Campinas, SP: Mercado das Letras, 2008, pág.39.

SOLIGO, A., GRANDIN, L. e ALEXANDRINO, R. Com quem trabalham os professoresformadores? Representações sociais na prática formativa. In. VICENTINI, A. A.F...[et al], (orgs). Professor - formador: Histórias Contadas e cotidianos vividos. Campinas, SP: Mercado das Letras, 2008. págs.63-82.

VAILlANT, D. Formação de Formadores: Estado da Prática. Preal, Online, out. 2003, v. 25, n. 25, p.1-60,. Acesso em: 28 dez. 2015 
VICENTINI, A. A.F...[ et al], (orgs). Professor - formador: Histórias Contadas e cotidianos vividos. Campinas, SP: Mercado das Letras, 2008.

TÜRCKE, C. Sociedade Excitada: filosofia da sensação. Campinas, SP: Ed. Unicamp, 2010.

WEISZ, T. O diálogo entre o ensino e a aprendizagem. São Paulo, SP: Ática, 2000. Cap.8. p.117133.

Resumo: É fato que nos últimos anos, em nosso país, o cenário da educação brasileira vem atravessando momentos de muitas mudanças, incertezas e contradições. Na mídia, nos discursos políticos das diferentes instâncias públicas, sejam municipais, estaduais ou federais, há um ponto comum quando se trata de propostas e ações para enfrentar esses dilemas: o investimento na formação continuada de professores e profissionais da área em geral. Neste artigo pretendemos tecer algumas considerações sobre o sentido da atuação do formador externo no âmbito dos programas de formação continuada de modo a contribuir para o fortalecimento de uma instituição cada vez mais desacreditada e desgastada aos olhos da população.

Palavras Chaves: Formação Continuada - Formador externo -Educação.

\begin{abstract}
It is a fact that in recent years, in our country, the scenario of Brazilian education has been going through moments of many changes, uncertainties and contradictions. In the media, in the political discourses of the different public instances, whether municipal, state or federal, there is a common point when it comes to proposals and actions to face these dilemmas: investment in the continuing education of teachers and professionals in the area in general. In this article we intend to make some considerations about the direction of the external trainer in the context of the programs of continuous formation in order to contribute to the strengthening of an institution more and more discredited and worn out in the eyes of the population.
\end{abstract}

Key Words: Continuing Education - External Trainer -Education 